\title{
Using of Paired Pulses of Light to Assess the Operability of Physical Training and Sports
}

\author{
Michael M. Polevschikov \\ Nadezhda I. Palagina \\ Yuliya A. Dorogova \\ Mari State University, Yoshkar-Ola, Russia \\ Email:mmpol@yandex.ru \\ Valeriy V. Rozhentsov \\ Volga State University of Technology, Yoshkar-Ola, Russia \\ Email: vrozhentsov@mail.ru \\ Maria L. Blinova \\ Mari State University, Yoshkar-Ola, Russia, Interregional Open Social Institute, Yoshkar-Ola, Russia \\ Email: airam8@mail.ru
}

\section{Doi:10.5901/mjss.2015.v6n3s7p221}

\section{Abstract}

Itwasdevelopedamethodofevaluationofindividualefficiencyduringphysicaltrainingandsports, allowing to increase the accuracy of its diagnosis. The method is based on determining the time of using the pair of excitation light pulses indicative of the speed of excitation in the central nervous system. It was described the results of evaluation of physical performance of athletes aged 20 to 22 years, specializing in cyclic sports: long-distance runners and skiers. Qualification of testee is I discharge and candidates master of sports. Probationers were pre-trained in a certain threshold pulse interval (PI), in which two pulses in a pair merge into one. When bicycle exercise load equal to $75 \%$ of maximal oxygen consumption due, subject periodically determines the threshold PI. According to the obtained values of the threshold PI plotted in the coordinates of its dynamics «the threshold PI the testing time». Testing was repeated after two days of rest to the load increased by $50 \mathrm{~W}$ until the threshold PI dynamics graph will have a downward trend. The level of physical performance is determined by the previous graph threshold PS having a «plateau», the volume of work performed by formula: $A=W \cdot t$, where $W$-load power, $W ; t$-testing time, sec.

Keywords: training-session, performance evaluation, method of paired light pulses.

\section{Introduction}

The concept of «physical performance» is widely used in the physiology of physical training and sports, and is an integral indicator of the final result of adaptive changes in the human body (Gudkov, TedderYu.R., Degteva, 1996), its physical capabilities (Astrand, Rodahl, 1977).The literature indicates that the conventional interpretation of the concept of «physical performance» psychologists don't have yet. The term «physical performance» and sometimes just «performance» includes very different content (Aver'yanov, Kapustin, Vinogradova et al. 1992).

The problem of studying efficiency, despite the large number of studies, remains relevant. In physical training and sports is reflected in the general physical preparedness and depending on the specifics of the sport to a greater or lesser extent affect the fitness of the athlete, and through it -the sports results.

Most authors point to the need for an integrated approach to the diagnosis of performance based on methods of assessing performance or condition of a number of physiological and psychological functions. However, the main focus is to find informative instructional techniques for the diagnosis of biochemical, physiological or psychophysiological indicators.

The first and very sensitive indicator of changes occurring in the body is a psychophysiological state of the human body. It was determined the influence of physical activity on the parameters of the analyzer systems, found a decrease in their functionality and increase their level of thresholds (Krasnov, 2003). We previously demonstrated the possibility of 
assessing performance using paired light pulses (Polevshchikov, Rozhentsov, 2009).

Purpose of thesis is to develop a method for assessing individual performance during physical training and sports, allowing it to increase the reliability of diagnosis.

\section{Methods and Materials}

The method is based on determining the time of excitation, which characterizes the rate of excitation of the central nervous system (CNS). The study involved 10 trained a certain threshold pulse interval (PI) athletes aged 20 to 22 years with normal vision, specializing in cyclic sports: long-distance runners and skiers. Qualification of probationers is the I discharge and candidates master of sports.

Testing was performed in the morning from 9 to 12 hours, light pulses were presented binocularly. The subject is asked by a bicycle ergometer test with constant load equal to $75 \%$ of maximal oxygen consumption and impose a sequence of paired light pulses with a duration of $200 \mathrm{~ms}$, separated initial PI equal to $70 \mathrm{~ms}$, repeated through the constant time interval $1 \mathrm{sec}$.

During the test, periodically, every 2 minutes, determined by the method of successive approximation PI threshold at which the two pulses in a pair are merged into one (Polevshchikov, Rozhentsov, 2009). According to the obtained values of the threshold PI plotted in the coordinates of its dynamics «the threshold PI - testing time». Testing stopped when the threshold value of PI decreases sharply or by decision of a doctor.

The test was repeated after two days of rest with the load increased according to the recommendations of $50 \mathrm{~W}$, as long as the threshold PI dynamics graph will have a downward trend. The level of physical performance was determined by the previous graph threshold pulse interval having a «plateau» in terms of the work performed A by formula:

$\mathrm{A}=\mathrm{W} \cdot \mathrm{t}$,

where $\mathrm{W}$ - load power, $\mathrm{W} ; \mathrm{t}$ - testing time, sec.

\section{Results}

As an example, the test results of the testee T., aged 20, 1 digit for cross-country skiing. The testee performed using a bicycle ergometer test model «Kettler X1» № 7681-000 in a sitting position with the speed of pedaling $60 \mathrm{rev} / \mathrm{min}$. The value of a constant power load is taken to be $195 \mathrm{~W}$ corresponding to $75 \%$ of maximal oxygen consumption due to be determined in nomogramsof B.P.Prevarskogo.

During testing, the doctor performs continuous monitoring of the status of the test on his appearance, heart rate and blood pressure changes which served as a doctor testing grounds for termination. Schedule dynamics threshold values $\mathrm{PI}$ in the testing process is shown in Fig. 1.

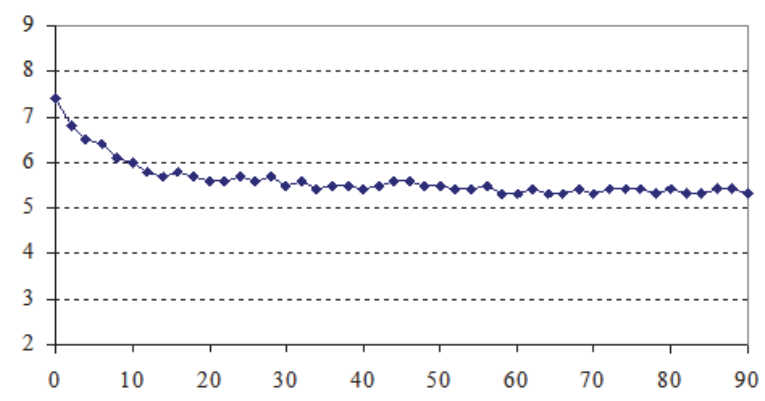

Figure 1. Flow chart of threshold PI when tested with a load of 195 watts. On the horizontal axis - time test, min; on the vertical axis - the value of the threshold PI, ms.

Analysis of the graph shows that in the testing process is no sharp change in the values of the threshold PI. This indicates that the status of the CNS does not change during testing, fatigue of testee under a given load, based on its state during the test does not occur. Testingstoppedontheadviceofadoctor.

The testee $\mathrm{T}$. retest after two days of rest with a load of $245 \mathrm{~W}$, corresponding to $94 \%$ of maximal oxygen consumption due. Schedule dynamics threshold values PI in the testing process is shown in Fig. 2. 


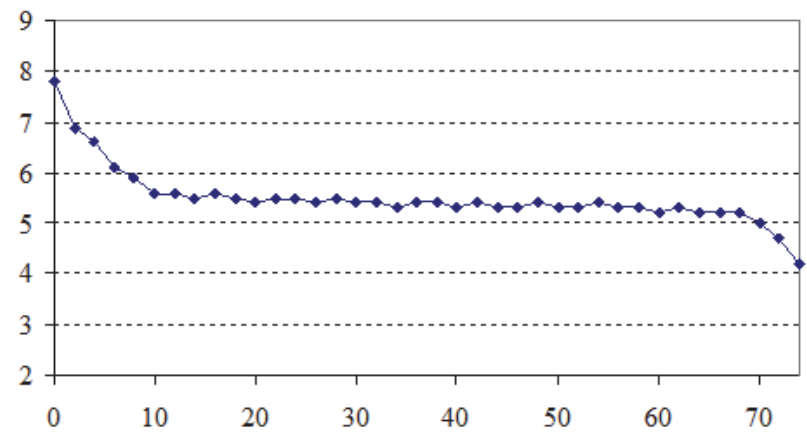

Figure 2. Schedule dynamics of the threshold PI when tested with a load of 245 watts. On the horizontal axis - time test, min; on the vertical axis - the value of the threshold PI, ms.

Chart analysis of the threshold PI in the testing process determine the time of a sharp decrease in its value equal to 68 minutes. At that time, it's necessary to complete the test, otherwise the load further lead to fatigue, since the state of the central nervous system has dramatically changed.The testee T. retest after two days of rest with a load of $295 \mathrm{~W}$, corresponding to $114 \%$ due maximal oxygen consumption.Schedule dynamics threshold values PI in the testing process is shown in Fig. 3.

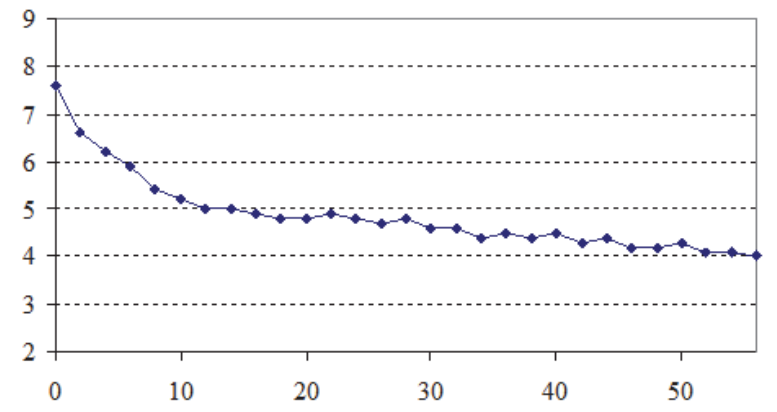

Figure 3. Schedule dynamics threshold PI when tested with a load of 285 watts. On the horizontal axis - time test, min; on the vertical axis - the value of the threshold PI, ms.

Chart analysis of the threshold PI during the test shows that a load equal to $295 \mathrm{~W}$, corresponding to $114 \%$ maximal oxygen consumption due for the testee $\mathrm{T}$. is excessive, since the graph has a downward trend. The level of physical performance defined by the previous graph threshold PI having a «plateau» (Fig. 2), the volume of work performed:

$\mathrm{A}=\mathrm{W} \cdot \mathrm{t}=999,6 \mathrm{KJ}$,

where W - load power, equal to $245 \mathrm{~W}$; t - testing time, equal to $4080 \mathrm{sec}$ (68 minutes).

Graphics output of the threshold PI at the beginning of the test after the end of the process of warming-up to «plateau» suggests that the CNS is in a quasi-stationary mode, i.e. the regulation of autonomic functions in all organs and systems of the body are finished and the whole body is really in a state of optimal health. In the quasi-stationary regime is observed variability of the threshold PI due randomness CNS as a complex biological object.

Changes in the body due the development of fatigue during testing are as incoordination processes in organs and systems of the body, increasing the physiological value of work (Smirnov, 1984). Condition of the central nervous system, responsible for the regulation of the processes occurring in the human body is changing. CNS goes into tension, evidenced by a sharp decrease in the threshold PI between two pulses in a pair.

Overloading condition of the central nervous system in the testing process is constantly changing,the intensity of the regulation of autonomic functions continuously increases. With such a load in the testeemode is not optimum performance. 


\section{Discussions}

In relation to muscular work performance indicators are strength and endurance. The latter reflects a critical, temporary side efficiency, which is the initial concept for the treatment of fatigue.In this case, the relationship of the concepts of «efficiency» and «fatigue».Since both endurance and fatigue determine the state of health, it is believed that its usefulness can be interpreted only from the standpoint of the development process in the body fatigue.In turn, under fatigue is commonly understood as a temporary and reversible decrease in efficiency caused by work and working conditions (Cameron, 1973).

Among the tests that characterize the physical performance, the simplest is the study of muscle strength, which is regarded as an important indicator of the functional state of the neuromuscular system. However, muscle strength is not always correctly reflect the state of fatigue, since it is necessary to take into account the load, perform a variety of muscle groups. Those muscles that work more intensively, the first show of force reduction, while other muscle groups still have the power to close to the original, and sometimes even exceed it. More reliable results than the measurement of force,provide research fatigue muscles.

One of the most common test is a test for determining the maximum oxygen consumption (MOC), which reflects the maximal aerobic power (Hill, 1927). The test determines the quantity of oxygen uptake when the surveyed work with increasing power. At some point in time, despite the capacity increase operation, the oxygen absorption ceases to increase, this value of the oxygen absorption is the value of MOC (McKenna, Heigenhauser, Mckelvie, et al. 1997). To determine MOC by the direct method gas-spirometricequipment is necessary, allowing to measure pulmonary ventilation and oxygen and carbon dioxide in the inhaled and exhaled air. When the indirect method based on the fact that between heart rate (HR), the intensity of physical work and the amount of oxygen consumption is a linear relationship, and that the MOC is achieved at a certain level of heart rate (McKenna, Heigenhauser, Mckelvie, et al. 1997).

While investigating the human performance, performing mostly physical work, are widely used sample dose of muscle loads generated by a bicycle ergometer (Müller, 1967). Y. Bushov et al. offer the results count rate of physical performance equal to the ratio of increase in pulse rate for a stepwise increase in power load, for example, from 40 to 80 watts of power to the value of growth. Rate of physical developmentcoefficient depends on the initial state of the body and at the same time serves as a stable characteristic, reflecting individual capabilities. Increasing the rate of physical developmentshows a decline in physical performance.

To determine the total physical capacity of man apart from the test MOC it used tests of Valunda - Shestranda or test PWC170, as well as the threshold level of anaerobic metabolism, which reflects the effectiveness of aerobic process and corresponds to the intensity of muscle activity at which oxygen is clearly not enough for a full energy and dramatically enhanced processes without oxygen (anaerobic) energy education (Shirkovets, 1986).

I.E. Ruban et al. consider that the degree of adaptation to physical stress is determined by the individual relations of aerobic and anaerobic energy production mechanisms, so they offer to determine separately the aerobic threshold, indicating the end of a purely aerobic forms of work, and the anaerobic threshold, indicating the beginning of the restructuring of energy supply.

These figures are some critical points, which you can set the overall preparedness of athletes and specific changes in the energy system of muscle activity in response to the load imposed (Lazareva, 2003). However, these tests reflect only the energy capacity of skeletal muscle systems. Meanwhile, according to R. Margaria, who introduced the concept of the scientific revolution of the energy source, it is equally important to know the capabilities and efficiency of each of the sources, including anaerobic (Zaytseva, Son'kin, Burchik, et al.1997).

Proposed the test, allowing on the basis of data of the bicycle ergometryassess anaerobic capacity athlete Vingeytsky anaerobic test is simple and available, use a physiological approach to the evaluation of test results. During the test, at first athletes for 2 minutes, perform a load with relatively little resistance and cadence with two or three 6-5second acceleration. Then after a 2- minute rest is done the main load, consisting in a 30-second pedaling as possible cadence.Pedaling resistance is adjusted individually according to the level of physical performance on the test PWC 170 . Every $5 \mathrm{sec}$. to load in registration rate and cadence that allows ultimately rely load power (W). Evaluation of the results of testing performed by the average load power for 30 seconds.Obviously, the higher the power, the greater the maximum intensity of the mechanical work may perform sportsman (Belotserkovskiy, Lyubina, Gorelov, et al. 2004).

A.T.Ketkin and V.G.Evdokimov proposed measure physical performance - watt pulse (Ketkin, Evdokimov, 1997), which reflects the adaptation of conversion in the activities of the cardiorespiratory system during adaptation to physical activity. It is closely linked with the standard performance indicators defined in the tests of the MOC and PWC170 and has the following advantages:

- watt-pulsedetermined easily by mass screening, since it allows the standardization of external action, not 
reaction of the organism;

- watt-pulse is less sensitive to changes in the recorded physiological parameters and to the influence of the neuro- emotional factors;

- $\quad$ at determining watt-pulse phenomenon of the residual fatigue does not occur due to low power applied stress tests.

As an indicator of physical performance in studies using ventilation or respiratory minute volume, which refers to the actual amount of air passing through the lungs during 1 min. The value of pulmonary ventilation can be determined by Douglas - Holden, lies in the fact that the subject breathes through a respirator connected to a rubber hose with a bag of rubberized material.Valve bag device such that during inhalation ambient air enters the lungs, and exhaled - is collected in the bag. After the test, the bag with the exhaled air is connected to the gas clock and measure the respiratory minute volume (Lazareva, 2003).

V.M. Pokrovsky et al. found that the width of the range of cardiorespiratory synchronism increases with increasing physical performance. The phenomenon of cardiorespiratory synchronism, manifested in the fact that at the heart of every breath makes one cut, has been known for over 100 years.Synchronization range is determined by the difference between synchronized heart rate and breathing on the maximum and minimum boundaries of cardiorespiratory synchronism.At the same time, regardless of the age of the common patterns are marked indicator bandwidths cardiorespiratory synchronism people with different types of personalities. The widest range detected in phlegmatic, shade less - in sanguine, much smaller - from choleric and melancholic.

The modern approach to the definition of efficiency is based on the use of ergometric methods, analyzing the external manifestations of muscle activity - the intensity of load and execution time.This approach is based, as the V.V. Zaitseva and al., to the works of V.S. Farfel, who on the base of the characteristics of cross-country ergometric exercise has developed its own concept of «zones of relative power». Later, he was able to be closely linked with the concept of energy model R. Margarita giving to her finished look and important research - specific bio-energy content. The advantage of the scheme V.S. Farfel is that it embraces the whole range of available human loads, tying the load power with time limit for its implementation. When the time limit with the power for the maximum power source is a characteristic of its capacity.In this case, traditionally measurable indicators - the anaerobic threshold and the critical power corresponding MOC - are characterological point of defining the boundaries of cardinality capabilities of different energy sources. Until recently, this scheme was mostly theoretical, since, being based on the results of world records in running, characterized the limits of human muscle possibility, but not a particular individual.

Recently, it was succeeded in «audit» of these concepts and adapt «curve of Records» for the study of energy capacity of the muscular system of the individual.When this time limit curvetlim muscular exercise can be represented in the form of mathematical equations using Mueller:

$\mathrm{t}_{\text {lim }}=\mathrm{e}^{\mathrm{b}} \mathrm{W}^{-\mathrm{a}}$,

where $\mathrm{W}$ - loadpower, $\mathrm{e}$ - base of the natural logarithms, «a» $u$ «b» - individual constant.

Unlike other options description ergometric dependencies found in the literature, the coefficients of Mueller have clear physiological meaning: the coefficient «a» represents the degree of heterogeneity or homogeneity of skeletal muscle tissue, and the coefficient of «b» is an indicator of aerobic capacity energy source. Estimating the maximum duration of this test at two different power loads, it is possible to determine the value of individual constants and plot the time limit of muscular work. This allowsto calculate all characterological terms, ie to determine the boundaries of zones of power and capacity of each of the energy sources. The area under the curve will correspond to conditionally integrated functionality in all accessible this person load range. Described the possibility of ergometric calculations allow to use them to assess the performance and governance of workouts (Lazareva, 2004).

However, the performance indicators used aerobic weakly associated with human physiological indicators in the performance of the real work, and indicators characterizing the function of only the cardiorespiratory system can not evaluate all the factors that ensure the success of the physical activity of the person.Assessment of physical performance of athletes on the basis of measurement of MOC or load power at which the heart rate stabilized at 170 beats / min, can lead to completely wrong conclusions.So the value of $\mathrm{PWC}_{170}$ gymnasts qualifications vary in the same range as that of the untrained people.But this does not mean that physical performance is the same. The value of the MOCis not informative and relative (per kg body weight). This reflects not so much working capacity of the organism as an integrated activity of oxidative mechanisms, and between these two concepts can not be equated. It is well known since the days of classical studies P.-O. Astrand showed that with age after 10 years of relative magnitude of the MOC does not change, whereas the actual performance continues to increase up to 20 years, and sometimes longer.

Studies indicate that there is no single indicator that would be able to reflect performance over the entire range of 
available human loads. This is due to the fact that power in different zones of the various operating mechanisms of energy. MOC value is more suitable for the prediction performance zone submaximal power than in other modes. This shows that the MOC actually reflects not the aerobic capacity as possible anaerobic glycolytic - power system operating in the most active zone submaximal power. ThevalueofPW $\mathrm{C}_{170}$ as the most suitable for evaluating the performance in anaerobic-glycolytic zone, but unlike the MOC it is able to satisfactorily describe the performance test in a stepwise rising power. For the prognosisof the performance in the conditions of the test increased stepwise power most informative indicator is the anaerobic threshold, but in the zone of maximum power, this figure is less informative.

Decreased performance, according to most authors, is manifested in violation of state of several body functions (Bodrov, 1988). However, it is clear that at the same efficiency of the functional changes in the body in individuals can be very different. It depend on physical fitness, professional readiness, motivation to work and other factors. The same reduction in performance of different people will be accompanied by a variety of functional shifts in size of various body systems.For this reason, many psychologists consider it advisable to simultaneously use a set of techniques for assessing the performance.

While executing an integrated approach, based on the evaluation of several indicators related to different levels of functioning of the body - physiological, psycho-physiological, behavioral, etc., difficulties arise due to the fact that changes in various parameters in individuals expressed differently. The need summary measureis obvious that would allow one number to reflect changes in performance of the human body at its various parameters.

Analyzing the data in the literature, there are three types of integrated indicators based on different mathematical and statistical approaches:

- integral index of the first type - the geometric mean ratio of the subject with a sequence number $\mathrm{i}$ :

$$
\bar{x}_{g, i}=\sqrt[k]{\Pi x_{i, j}}=\sqrt[k]{x_{i, 1} \cdot x_{i, 2} \cdot \ldots \cdot x_{i, j} \cdot \ldots \cdot x_{i, k}}
$$

wherex - value of a single indicator; $i=(1,2, \ldots, n)$ - serial number of the subject; $n$ - number of examinees; $j=(1,2, \ldots, k)$ - number of single indicator; $\mathrm{k}$ - number of indicators.

Lack of geometric mean index lies in its specificity - it is adequate only for a given set of tests, with the exception of one of the variables in the set or adding a new index significantly changes the value of the integral geometric. Therefore, thegeometricparametersindifferentresearchersusuallycomparable.

This disadvantage is eliminated by replacing the concrete results of measurement options expressed in the new scale measurement unit which is called standard units, points, stans, T- scale units, etc.More likely to use a 10 - point scale, but there are a 5-, 20-, 100 - point scale, which makes it difficult to compare the results of different studies;

-integral component of the second type of the subject with a sequence number $\mathrm{i}$ is defined as the arithmetic mean value:

$$
\bar{x}_{i}=\frac{x_{i, 1}+x_{i, 2}+\ldots+x_{i, j}+\ldots+x_{i, k}}{k}
$$

wherex - value oftheassessment; $i=(1,2, \ldots, n)$ - serial number of the subject; $n$ - number of examinees; $j=(1,2, \ldots, k)$ ' number of single indicator; $\mathrm{k}$ - number of indicators.

A significant drawback of this indicator is ignoring the variability of different values of the individual indicators, it does not take into account the different meaning and indicators to assess performance (Goretskiy, Maksimovich, Shevchenko, et al. 1991).

To assess the individual changes of selected indicators, taking into account their initial level and direction of changes in the valuation indicators suggested as a ratio, the numerator of which shows the change in the index during the study period, and the denominator - its background value [30]. al.1982):

Shift amounts of individual indicators $\Pi_{j}$ suggested to calculate by the formula (Petukhov, Udarova, Likhacheva et

$$
\Pi_{j}=\frac{\beta-\gamma}{\alpha+\beta+\gamma},
$$

where $\Pi_{\text {jmaychangefrom }-1}$ to +1 , negative index indicates a deterioration; $\beta$ - the number of dimensions in which the performance improved; $\gamma$ - the number of dimensions in which the performance deteriorated; $\alpha$ - number of measurements in which changes were observed in comparison with the data obtained before the operation.

In terms of the integral of the second type can be more important to consider the introduction of indicators of significance coefficients Cs, also referred as «weighting coefficients». For a more significant indicators Cs is greater than one, for less important - less than one. A different approach to the establishment of Cs offers (Dyadichkin, 1990), calling them «weightscoefficients» WC. In his interpretation of WC must provide approximately the sameintegrable shift indicator 
in the course of work on the optimal values for each test of the function $X_{\text {opt.According to V.P. Dyadichkin, when }}$ calculating the integral index is impractical to introduce any new measurement scale, it is necessary to average not the absolute results of the measurements, but relative shifts indicators ( for machining - expressed as a decimal ). Relative shift indicator values V.P. Dyadichkin calls «stress index function» $H$, the formula for its calculation is:

$$
\mathrm{H}=\left|1-\frac{\mathrm{X}_{\mathrm{i}, \mathrm{j}}}{\mathrm{X}_{\text {опт }}}\right| \cdot \mathrm{WC} \text {, }
$$

whereXoptmay be the result of a single measurement of its characteristic function units and an average of several measurements for a certain period. Sign of the shift does not matter, because taking the absolute difference between the unit and the relative shift that makes «stress index»H convenient for computer processing, because for the same program processes data from a study of various functions, not paying attention to what increases or decreases the value of the index in the development of fatigue.

- more objectively and accurately take into account the importance of the individual tests in the integrated performance of the third type, based on regression models. In this case, the weighting factors often determine the coefficients $b j, j=(12, \ldots, k)$ in the equation of multiple regression straight :

$$
\mathrm{y}=\mathrm{b}_{0}+\mathrm{b}_{1} \mathrm{x}_{1}+\mathrm{b}_{2} \mathrm{x}_{2}+\ldots+\mathrm{b}_{\mathrm{j}} \mathrm{x}_{\mathrm{j}}+\ldots+\mathrm{b}_{\mathrm{k}} \mathrm{x}_{\mathrm{k}}
$$

The above equation is based on the method of least-squares regression assumptions of linearity and the approach of the type of distribution to the normal version of all $k$ samples. The «t» are valid for the direct nature of the relationship between $x_{j}$ and $y$. This formula is similar to the formula for calculating the integral index of the second type, and the regression coefficientsbjare similar to coefficients $\mathrm{C}_{\mathrm{s}}$, but in the regression equation using the sum of productsbj $\mathrm{x}_{\mathrm{j}}$, and in terms of the integral of the second type - the arithmetic mean of the worksKj $x_{j}$. Differences are also in the free term of the regression equation $b_{0}$, which often tends to zero in many methods is not considered.

A significant drawback of the integral indices of the third type, as well as the geometric mean is their specificity. With the exclusion of one of the values of $x_{j}$ or adding a new indicator set $x_{k+1} i t$ 's necessary to rely a new regression equation, and the values of the coefficients $b_{j}$ change. Using multiple regression equation for the integral evaluation is only possible if there is an accurate external criterion «y», which for many situations there is absent. The assumption of linearity relations between the external criterion and independent individual indicators limits the use of regression models.

Recently, unfortunately, no medicine and physiology or mathematical statistics do not provide the comprehensive recommendations how to obtain an estimate for the integral indicators because do not have the data necessary to determine the reliability of the various functions independently of the conditions in which these functions are shown. There is no consensus on the most appropriate system of surveillance, monitoring and forecasting performance.

Integration tests require the participation of several qualified specialists using complex and expensive equipment. Therefore, a significant number of works devoted to the development of indirect methods of assessing performance (Astrand, Rodahl, 1977). Many researchers have noted that tracking of psycho-emotional stress and psycho-functional state allows, under certain conditions, to predict the possible deterioration of human performance before it happens. At the same time as an informative indicator of changes in the psycho-functionalhuman condition use vegetative reactions, such as electrodermal resistance and galvanic skin response (Arakelov, Shott, 1998). However, when registering electrophysical parameters characterizing the psycho-functional human condition, a man himself and the means of measurement are in bilateral cooperation, the extent and nature of which affect the accuracy of measurement.

The basic properties of nervous processes (strength, lability, mobility, agility, balance), their level of functional stress, psychoemotional state of the body in many ways determine the overall adaptation strategy, its effectiveness and psychological preparedness training-competitive activity, cause athlete's individual behavior in different sports situations. Determination of physiological parameters of athletes allows to estimate the functional state of the central nervous system, the degree of fatigue during physical training and sports, to set individual volume of physical activity and its intensity, preventing the state of fatigue.

However, the data of the literature review and interviews with physiologists have shown that there are few methods that have high reliability and information content determined the functional state of the central nervous system in the dynamics of the athletes.

The proposed method of assessing performance with using a pair of light pulses by analyzing the dynamics threshold PI can be used directly in the physical training and sports and to improve the accuracy of its diagnosis.

\section{Conclusion}

Method of assessing individual performance during physical education and sport through the analysis of the dynamics of 
the threshold PI, which characterizes the rate of excitation in the central nervous system is presented. The study found that the proposed method can quickly determine the functional state of the central nervous system, the degree of fatigue in sports, adjust individual volume and intensity of physical activity, preventing the development of fatigue.

\section{References}

Alferova, I.V., Turchaninova, V.F., Golubchikova, Z.A. et al. (2003) Analysis and evaluation of the functional state of the cardiovascular system of astronauts during long space flights. Fiziologiyacheloveka, 6, 5-11.(In Russ.).

Arakelov, G.G., Shott, E.K. (1998) RAG as a manifestation of emotional and motor components indicative of stress. Psikhologicheskiyzhurnal, 4, 70-79.(In Russ.).

Astrand, P.-O. (1952) Experimental studies of physical working capacity in relation to sex and age. Copenhagen: Munksgaard.

Astrand, P.-O., Rodahl, K. (1977) Textbook of work physiology: Physiological bases of exercise. New York: McGraw Hill.

Aver'yanov, V.S., Kapustin, K.G., Vinogradova, O.V. et al. (1992) Assessment of the functional status and health of the operatorstechnologists of refineries. Fiziologiyacheloveka, 5, 119-123.(In Russ.).

Belotserkovskiy, Z.B., Lyubina, B.G., Gorelov, V.A. et al. (2004) Ergometric criteria of an anaerobic performance of athletes of different age and sex. Fiziologiyacheloveka, 1, 124-131.(In Russ.).

Bodro, V.A. (1988) Problems of the aircrew fatigue (concepts, causes, symptoms, classification). Fiziologiyacheloveka, 5, 835-843. (In Russ.).

Borilkevich V.E. (1983) On the concept of the phenomenon of «Physical performance». Teoriyaipraktikafizicheskoykul'tury, 9-10, 18 19. (In Russ.).

Bushov,Yu.V., Ershov, A.F., Os'minin, F.V. et al. (1985) Effect of moderate hypoxia on the performance of a human operator, depending on individual circumstances. Fiziologiyacheloveka, 2, 258-261.(In Russ.).

Cameron, C.A. (1973) Theory of fatigue. Ergonomics, 5, 633-648.

Dutov, V.S., Severin, A.E., Shastun, S.A. et al. (1997) Dynamics of parameters of the cardiac rhythm during a stepwise increasing load on the cycle ergometer in the examinees with different levels of physical performance. Teoriyaipraktikafizicheskoykultury, 4, 1415.(In Russ.).

Dyadichkin, V.P. (1990) Quantitative evaluation of the integrated operating voltage at the mental and physical labor. Gigienaisanitariya, 1, 34-37.(In Russ.).

Goretskiy, S.S., Maksimovich V.A., Shevchenko L.S. et al. (1991) The method of integral evaluation of the impact of the working environment on the body of the workers. Fiziologiyacheloveka, 4, 121-125.(In Russ.).

Grandjean, E. (1968) Fatigue: its physiological and psychological significance. Ergonomics, 5, 427-436.

Gudkov, A.B., Tedder, Yu.R., Degteva, G.N. (1996) Some features of the physiological reactions of the body of workers under expeditionary rotational basis of work organization in the Arctic. Fiziologiyacheloveka, 4, 137-142.(In Russ.).

Hill, A.V. (1927) Muscular movement in men. N.Y.: McBraun-Hill Co.

Karpman, V.L., Belotserkovskiy, Z.B., Lyubina V.G. (1969) PWC170- test to determine the physical performance. Teoriyaipraktikafizicheskoykul'tury, 10, 37-40.(In Russ.).

Ketkin, A.T., Evdokimov, V.G. (1997) Using the power ratio of the dosage of work to heart rate (pulse - watt for health evaluation). Fiziologiyacheloveka, 2, 317-324.(In Russ.).

Korol,' V.M., Son'kin, V.D. (1983) Muscle performance of adolescents of 13-14 years. Fiziologiyacheloveka, 6, 907-912.(In Russ.).

Krasnov, M.M. (2003) Ophthalmic Practice and overall health. Vestnikoftal'mologii, 4, 4-6.(In Russ.).

Lazareva, E.A. (2003) Interdependence of overall physical performance and energy types of muscular activity athletes - sprinters and stayers. Teoriyaipraktikafizicheskoykul'tury, 9, 42-44.(In Russ.).

Lazareva, E.A. (2004) Ergometer testing of athletes, sprinters and stayers using variables equation of Muller. Teoriyaipraktikafizicheskoykul'tury, 10, 36-37.(In Russ.).

Margaria, R. (1976) Biomechanics and energetics of muscular exercise. Oxford: Clarendon Press.

Masironi, R., Denolin, H. (1985) Physical activity in Disease prevention and treatment. Piccin: Butteworths.

McKenna, M.J., Heigenhauser, G.J.F., Mckelvie R.S. et al. (1997) Enhanced pulmonary and active skeletal muscle gas exchange during intense exercise after sprint training in men. Physiol., 3, 703-716.

Minakov,Yu.A., Polevshchikov, M.M., Rozhentsov, V.V. et al. (2013) Method of determining the level of human physical performance.Patent RF 2491016, Byul. 24. (In Russ.).

Morehouse, L.E., Beckman, E.L. (1967) Exercise tolerance of Sealab II aquanauts. J. Sport. Med., 6, 163-165.

Morehouse, L.E., Beckman, E.L. (1968) Heart-paced ergometry. Biomed. Sci. Instrum., 3, 139-149.

Müller, E.A. (1967) TestleistungenzurBestimmung der körperlichenLeistungsfähigkeit. Arbeitswissenschaft, 2, 35-37.

Novikov, V.S., Blaginin, A.A., Shustov, E.B. et al. (1995) Psychophysiological evaluation of an acute physical fatigue. Fiziologiyacheloveka, 2, 24-29.(In Russ.).

Padilla, P.J., Martínee, L.E., Olvera, S.G. et al. (2000) Dinámica cardiopulmonary duranteunaprueba de esfuerzomáximo en atletasmexicanos de Resistencia. Arch. Inst. Cardiol. Mex., 3, 268-284.z

Petukhov, B.N., Udarova, N.S., Likhacheva, O.A. et al. (1982) Fatigue and adaptation abilities in the labor process.Fiziologiyacheloveka, 3, 457-462.(In Russ.).

Pokrovskiy, V.M., Abushkevich, V.G., Borisova, I.I. et al. (2002) Cardiorespiratory synchronism in humans.Fiziologiyacheloveka, 6, 100- 
103.(In Russ.).

Pokrovskiy, V.M., Abushkevich, V.G., Potyagaylo, E.G. etal. (2003) Cardiorespiratory synchronism: identification of a person, the dependence of the properties of the nervous system and the functional states of the body. Uspekhifiziologicheskikhnauk, 3, 6877.(In Russ.).

Polevshchikov, M.M., Rozhentsov, V.V. (2009) Method for determining fatigue rights.Patent RF 2364316, Byul. 23. (In Russ.).

Polevshchikov, M.M., Rozhentsov, V.V. (2009) Method of assessing the level of human physical performance.Patent RF 2372063, Byul. 31. (In Russ.).

Rozhentsov, V.V. (2008) Method of determining the excitation time of the visual analyzer rights.Patent RF 2342062, Byul. 36. (In Russ.).

Rubana, I.E., Aulik, I.V. (1986) Aerobic-anaerobic transition - the criterion of efficiency and dosing intensity in training children. Teoriyaipraktikafizicheskoykul'tury, 10, 41-44.(In Russ.).

Rubana, I.E., Dravniek, Yu., Daynauskas I. et al. (1988) Comparative characteristics of informativeness and reliability of methods for determining the boundaries of aerobic-anaerobic transition. Fiziologiyacheloveka, 2, 281-288.(In Russ.).

Shirkovets, E.A. (1986) Concept of anaerobic threshold in sports practice and critical analysis of methods for its determination. Teoriyaipraktikafizicheskoykul'tury, 3, 37 -40.(In Russ.).

Shirkovets, E.A., Kubatkin, N.I. (1975) Anaerobic threshold and critical speed - factors of management training of the athlete. Teoriyaipraktikafizicheskoykul'tury, 8, 19 - 25.(In Russ.).

Sjostrand, T. (1947) Changes in the Respiratory organs of workmen at one oresmelding work. Acta Med. Scand., 196, 687-699.

Smirnov, K.M. (1984) Intensity of work.Uspekhifiziologicheskikhnauk, 1, 76-99.(In Russ.).

Solodkov, A.S., Gorbenko, P.P., Ponomarev, V.P. et al. (1990) Features of functioning of the respiratory system in representatives of different sports when the load increases power. Fiziologiyacheloveka, 2, 112-119.(In Russ.).

Son'kin, V.D., Tiunova, O.V. (1989) Power zones: look after 50 years. Teoriyaipraktikafizicheskoykul'tury, 5, 56-58.(In Russ.).

Vaynbaum, Ya.S., Askerov, A.A. (1970) Step test with a submaximal load for the evaluation of physical performance. Teoriyaipraktikafizicheskoykul'tury, 2, 26 - 28.(In Russ.).

Zaytseva, V.V., Son'kin, V.D., Burchik, M.V. et al. (1997) Evaluation of informativenessergometric indicators of efficiency. Fiziologiyacheloveka, 6, 58-63.(In Russ.).

Zhbankov, O.V., Petrov, D.S., Golovina, V.A. (2003) The control system of psychophysical state of man as a tool for adaptive management in sport and learning process. Teoriyaipraktikafizicheskoykul'tury, 2, 20-23.(In Russ.). 
